\title{
Duration of Cough Vs Smear Positivity Among Patient Attending Tertiary Care Hospital
}

\author{
Dr. Gomathi. R.G, Prof. Rajagopalan.B, Dr. Sangeetha.M
}

Abstract: Early detection and prompt treatment is the basis of tuberculosis controlthrough reducing the reservoir of infection. The objective of the present study is to assess the yield of sputum smear positivity among chest symptomatics with cough duration of two weeks compared to three weeks or more .

Results: The yield of sputum positive cases of tuberculosis for 2 weeks $30 \%$ and for 3 weeks is $32 \%$.

\section{Introduction}

Tuberculosis is an infecious disease caused by mycobacterium tuberculosis .Transmission occurred by infectious droplets .Source of infection is sputum smear - positive pulmonary TB. Pulmonary tuberculosis contribute around $85 \%$ of total TB cases and these cases serve as main reservoir of infection ${ }^{1}$

India accounts for one fifth of global incidence of tuberculosis and tops the list of 22 high burden countries,is implementing RNTCP.As per the program guidelines,all patients presenting with cough of $>3$ weeks duration to be screened for tuberculosis by carrying out three sputum examinations ${ }^{2}$ Santha et al reported the increase in yield if the duration of cough for screening was reduced to $>2$ weeks ${ }^{3}$

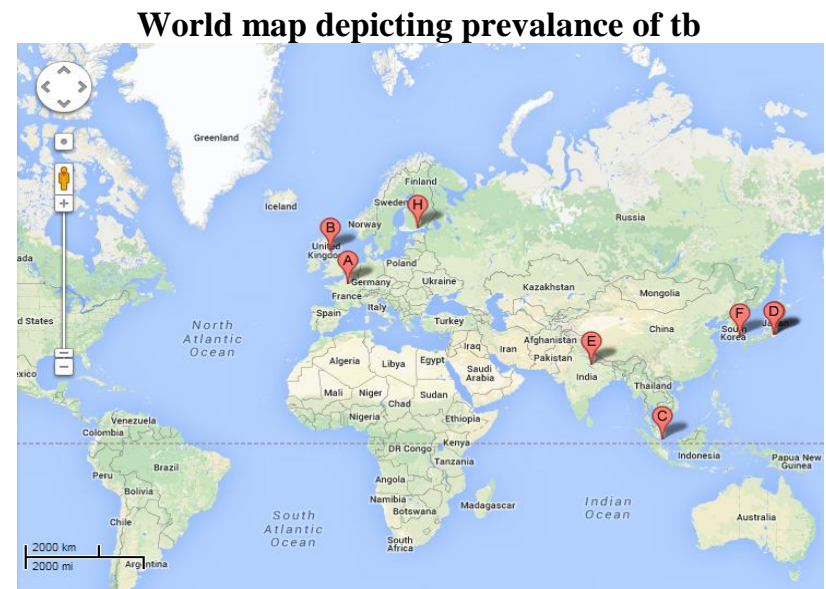

A. Union Internationale contre la Tuberculose et les Maladies Respiratoires (L'Union).

B. International Union Against Tuberculosis \& Lung Disease

C. The International Union Against Tuberculosis And Lung Disease.

Magnitude Of Tb-Global And Indian Scenario

\begin{tabular}{|c|c|c|c|}
\hline Global & $\begin{array}{c}\text { 9.4 Million } \\
(139 / \text { Lakh / Year })\end{array}$ & 11.1 Million & $\begin{array}{c}\text { 1.32 Million } \\
(19.6 / \text { Lakh/Year })\end{array}$ \\
\hline India & $\begin{array}{c}1.98 \text { Million } \\
(168 / \text { Lakh /Year })\end{array}$ & $\begin{array}{c}2.18 \text { Million (185/Lakh/Year }) \\
2.76 \text { Lakhs } \\
\text { Lakh/Year })\end{array}$ \\
\hline
\end{tabular}

\section{Rntcp Guidelines}

- Chest sympomatics $\geq 3$ weeks

- 3 Smear Examination

- 3 Categories

New Guidelines

- Chest symptomatics 2 weeks

- 2 Smear examination

- 2 categories 


\section{Objective}

- To assess the yield of sputum smear positivity among chest symptomatic with cough duration of two weeks compared to three weeks or more.

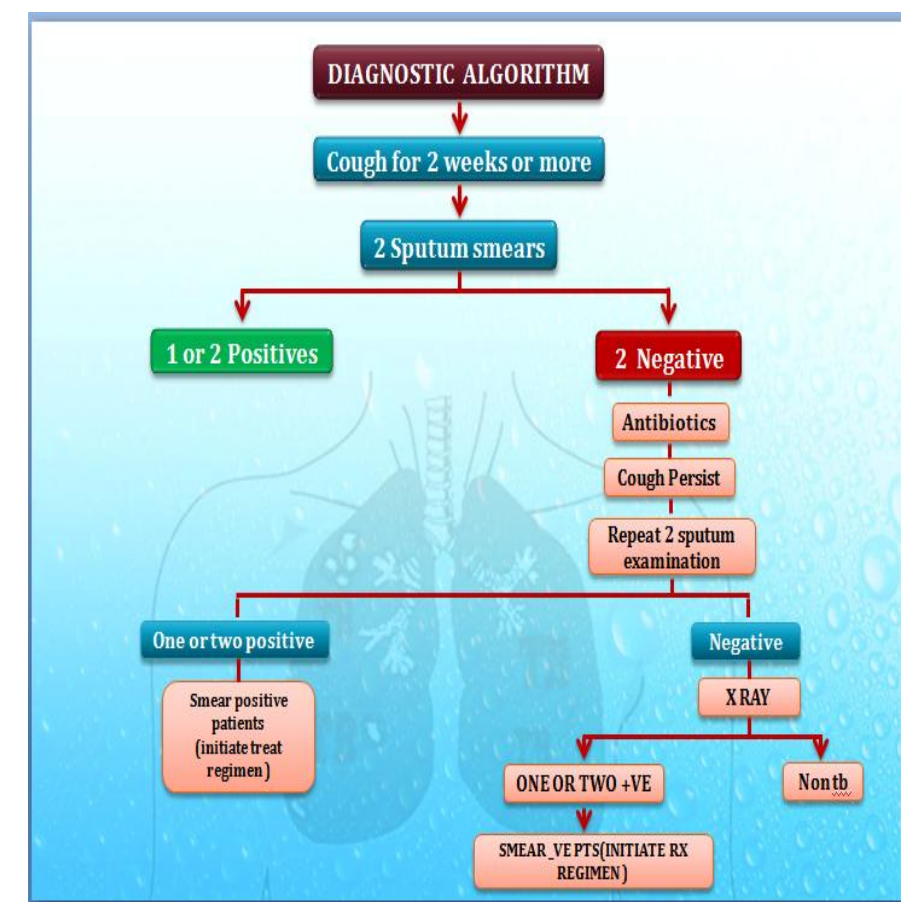

\section{Methodology}

- Study Design

- Study Location

- Sampling

: $\quad$ Cross Sectional Study

: $\quad$ Chest Op At Srmc

: Continous

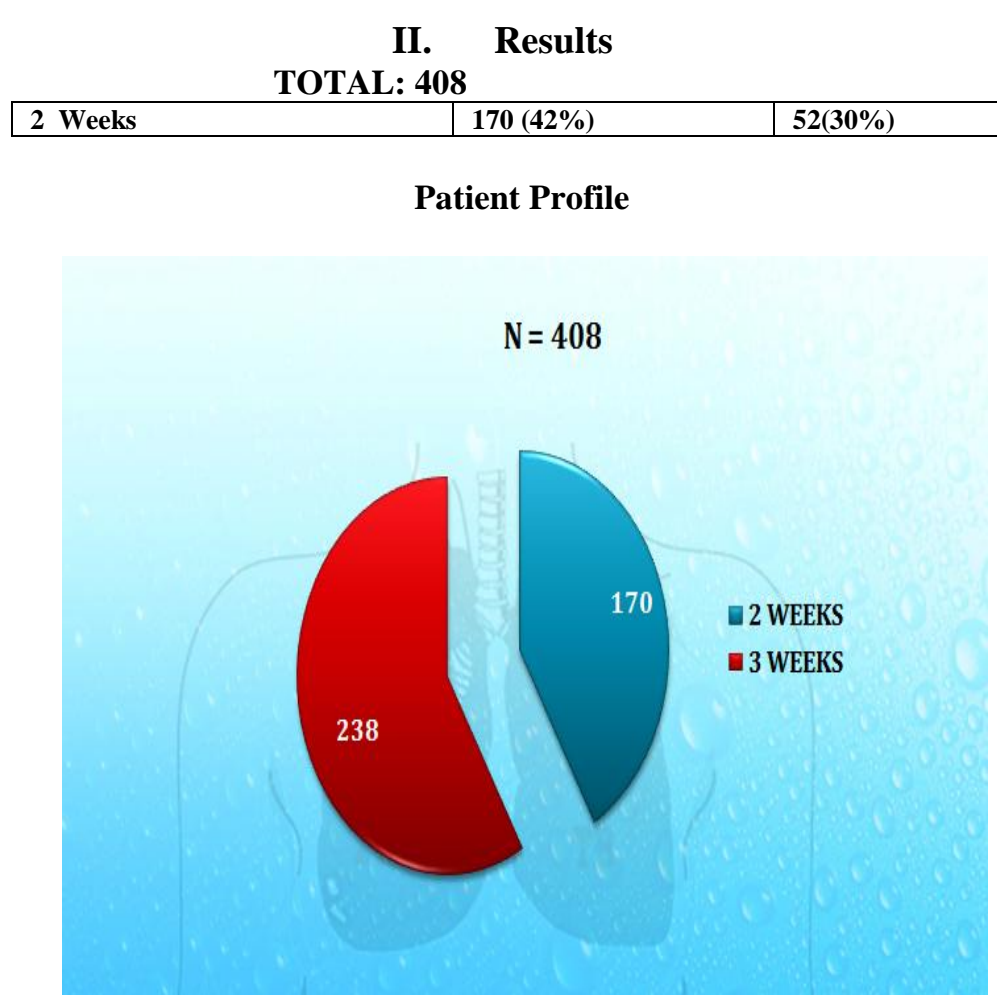




\section{Smear Positivity}

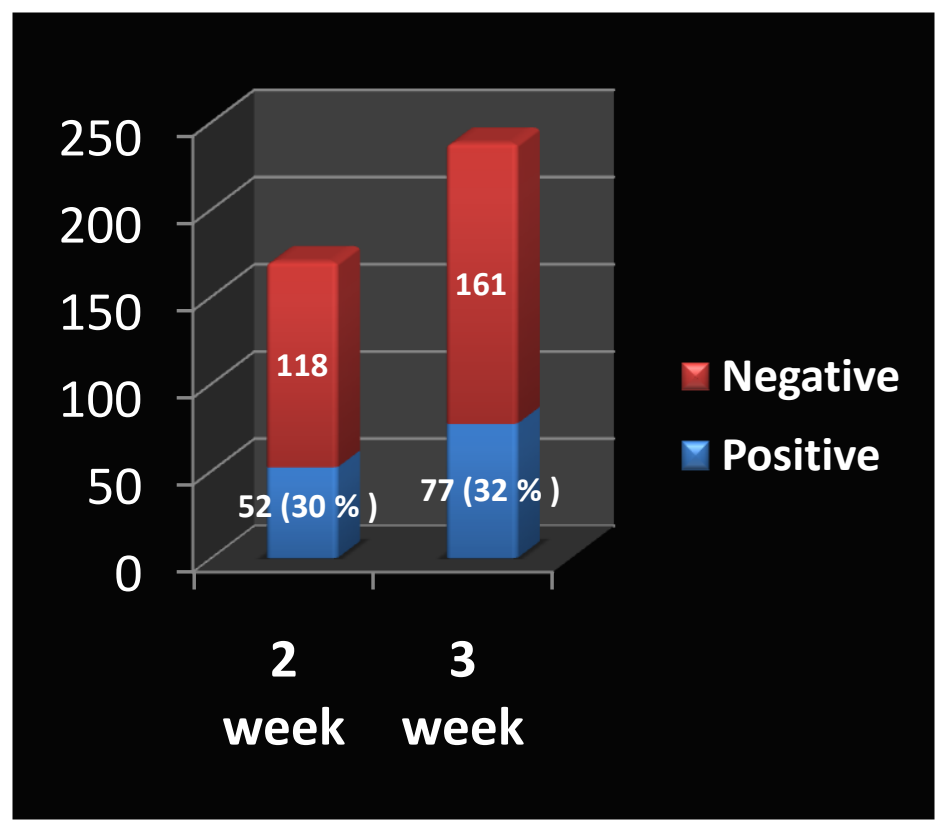

\section{Discussion}

According to the current RNTCP recommendations, any patient with cough of $\geq 3$ weeks should be screened for TB by doing three sputum examinations. This study confirms that the detection of smear positive PTB cases can be improved if the screening criterion is changed to a history of cough for $\geq 2$ weeks. In present study total 408 patients were included in the study, duration of cough for 2 weeks ,smear + ve 52 patients $(30 \%)$ and smear -ve170 patients (42\%). duration of cough for 3 weeks, smear +ve 77 patients $(32 \%)$ and smear -ve 238 patients $(58 \%)$. Indian I tubere $2008 ; 55(2), 77-83$, A, Thomas et al Multicentre study which showed 2 weeks symptoms showed good sputum yield ${ }^{4}$. Online I Health Allied Scs 2009,8(2);7 Nimbarte et al ,done at wardha revealed that by screening patients with symptoms >2 weeks improved yield by 1.3 times $^{5}$. Niger I clin pract 2012 oct-Dec; 15(4):430-5 Hamid S et al Study at Kashmir concluded that as sputum positivity yield was same with symptoms $>2$ weeks, It is an efficient way of diagnosing with scarce resources. ${ }^{6}$

A concern raised was that if the screening criterion for a chest symptomatic is reduced from $\geq 3$ weeks to $\geq 2$ weeks, there would be an increase in the laboratory work-load. However, we estimated from the study findings that the increase would only be in the order of two to three specimens per day if the number of specimens is also reduced from the present recommended three to two. This small increase is manageable by virtually all microscopy centres under RNTCP.

\section{Conclusion}

- The per cent of smear positivity was comparable amongst both groups.

- This reinforces RNTCP'S latest guidelines screening incorporating symptoms with 2 weeks cough for.

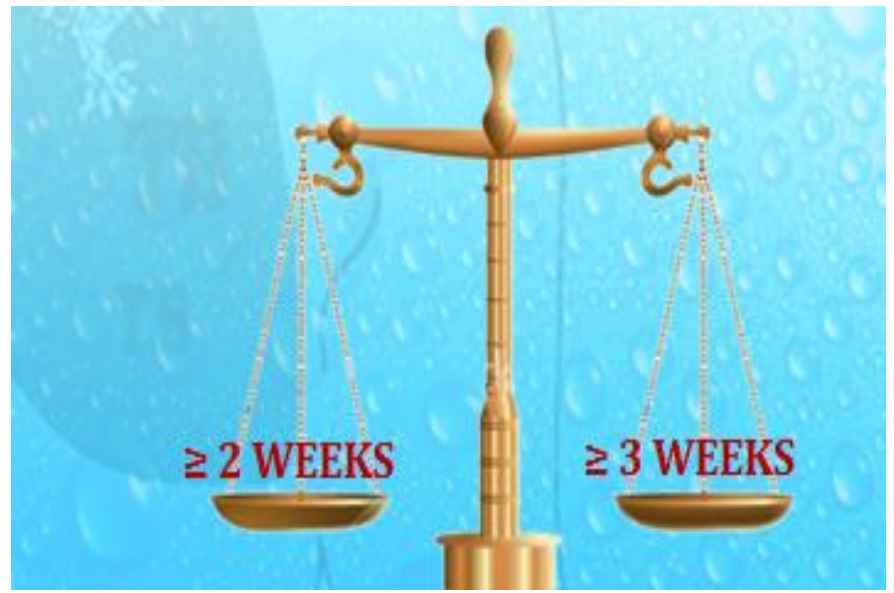


The yield of sputum smear positive PTB cases can be improved if patients with $>2$ weeks history of cough are screened to diagnose such cases. In addition, two sputum smear examinations are as efficient as three for diagnosis. There is no significant increase in the work-load by screening CSs with $>2$ weeks cough if a methodology of only two sputum smear examinations is utilised.

\section{Advantage}

Earlier detection and treatment leads to reduction in the source of infection in the community

\section{References}

[1]. Government of india .Managing the RNTCP programme in your area, a training course, module (1-4) central TB division, Directorate generate of health services, Ministry of health and Family welfare, New Delhi, April 2005;1-3.

[2]. Central TB division .Directorate General of health services (DGHS).Ministry of Health and family welfare. Government of India. Technical guidelines for tuberculosis controil, Delhi: DGHS, 2000.

[3]. Santha $\mathrm{T}$ et al ,comparison of coughof 2 and 3 weeks to improve detection of smear positive tuberculosis cases among outpatients in india. Int J Tuber Lung Dis 2005;1:61-68.

[4]. Indian I tubere $2008 ; 55(2), 77-83$, A, Thomas et al showed 2 weeks symptoms showed good sputum yield

[5]. Online I Health Allied Scs 2009,8(2);7 Nimbarte et al revealed that by screening patients with symptoms $>2$ weeks improved yield by 1.3 times.

[6]. Niger I clin pract 2012 oct-Dec; 15(4):430-5 Hamid S et al concluded that as sputum positivity yield was same with symptoms $>2$ weeks, It is an efficient way of diagnosing with scarce resources. 